\title{
Thermal decomposition of binder based on etherified starch to use in foundry industry
}

\author{
TG-DTG-DSC and DRIFT investigations
}

\author{
Karolina Kaczmarska1 ${ }^{1}$ (D) Beata Grabowska ${ }^{1}$ - Grzegorz Grabowski ${ }^{2} \cdot$ \\ Artur Bobrowski ${ }^{1} \cdot \dot{Z}^{1}$ aneta Kurleto-Koziol ${ }^{1}$
}

Received: 1 December 2016/ Accepted: 9 May 2017/Published online: 26 May 2017

(c) The Author(s) 2017. This article is an open access publication

\begin{abstract}
In this work, the main purpose was the determination of the thermal stability of the modified starch: sodium carboxymethyl starch (CMS-Na) used in foundry technology as organic binder for molding sand. The analysis of the course of decomposition of the starch material under controlled heating in the range of $20-500{ }^{\circ} \mathrm{C}$ was based on the results of thermal analysis methods (TG, DTG, DSC) in combination with the results of spectroscopic technology (DRIFT). The use of various methods of thermal analysis and spectroscopic methods was possible to determine more entirely the mechanism of the binder decomposition process comprising reactions at the molecular level with regard to the conditions prevailing in the mold. The onset temperature of degradation of the binder and at the same time the temperature at which it begins to lose binding properties were determined. It was found that the mechanism of the binder is multistage process. The decomposition of the starch binder CMS-Na involves the gradual evaporation of the water bound at a temperature of $20-120{ }^{\circ} \mathrm{C}$ and water constitutional starch in the range of 120-200 ${ }^{\circ} \mathrm{C}$, degradation of the binder in the temperature range $200-342{ }^{\circ} \mathrm{C}$ by breaking the glycosidic bonds in the polymer chains with the formation of volatile compounds and finally detaching the side groups and partial combustion of the starch material within a temperature range $342-500{ }^{\circ} \mathrm{C}$.
\end{abstract}

Karolina Kaczmarska

karolina.kaczmarska@agh.edu.pl

1 Faculty of Foundry Engineering, AGH University of Science and Technology, Reymonta 23, 30059 Kraków, Poland

2 Faculty of Materials Science and Ceramics, AGH University of Science and Technology, Mickiewicza Ave. 30, 30059 Kraków, Poland
Keywords Foundry polymer binders - Modified starch · Thermal analysis · TG-DTG-DSC $\cdot$ Thermal decomposition

\section{Introduction}

The binders in sand molds are a key component of determining the properties of the mold and castings produced by the binding strength of the matrix grains of sand. Although the binders currently used in foundries provide a production of durable molds and casting without defects, mostly they pose a serious threat to the environment. Thus, in the era of searching ecological solutions for foundry, there are observed strong interests in receiving new materials based on natural raw materials [1].

A potential replacement for toxic ingredients in sand molds is starch and its derivatives, which are tested for application not only as a binder but also an auxiliary material in the molding and core sands. The legitimacy of starch application in the technology of molding sand is dependent on the properties of the formulation starch (the conditioned by the biological origin), such as the ability to form viscous solutions, wetting ability and binding of the matrix grains of sand, susceptibility to cross-linking agents. Most frequently in technologies of molding sand, the potato and corn starches are used, but due to the fact that the prevalence of this biopolymer is almost limitless around the world, and the research on the possibility of use in the casting of starch derived from other plant species is conducted too. The starch as the polymer is not uniform in structure, and it is composed of two fractions: branched chains of amylopectin and linear chains of amylose [2].

However, the results of studies of the properties of molding sand bonded by starchy binders show that 
adhesives based on native starch are not a fully effective alternative to the currently used commercial products, and only its derivatives can guarantee obtaining molding sands with the relevant binding strength and functional parameters [3-6]. The example of modified starch with suitable properties for the foundry industry is carboxymethyl starch as a sodium salt (CMS-Na) produced by etherification of native starch in monochloroacetic acid (or its sodium salt) in the presence of sodium hydroxide [7, 8]. During the etherification, the polymer chains in place of the hydroxyl groups are substituted by hydrophilic groups (Fig. 1). The amount of hydrophilic groups in the polymer chains can be controlled quantitatively, and the structural effect of the modification process is characterized by a degree of substitution (DS). The presence of the hydrophilic group causes that the CMS-Na effectively swells up in cold water and affects the clarity of films and pastes. The etherification process also results in the stabilization of aqueous solutions of starch and reduces its tendency to retrogradation - thus all of the phenomena occurring during storage of the starch colloids, based on the creation of bonds between the starchy polymer chains starch and lead to an increase in its crystallinity at a low temperature [8].

The conducted own research related to application of CMS-Na in molding sands technology proved the legitimacy of using this modified starch as a binding material in the molds cured by chemical or physical agent (through conventional heating and exposure to electromagnetic radiation) $[5,6,9]$. However, from the point of view of pouring a liquid alloy into cured sand mold is to evaluate the thermal stability of a starch binder. Namely, too rapid thermal degradation of the organic binder in molding sand can result in the formation of significant casting defects (shape deformation, cracks, surface defects) $[10,11]$. On the other hand, the high thermal resistance may limit knockout properties or adversely affect the efficiency of thermal reclamation methods of used molding sands [12-14]. Thus, in this paper, the aim of the study was to characterize the mechanism of thermal decomposition of alternative organic binder on the example of CMS-Na with low degree of substitution.

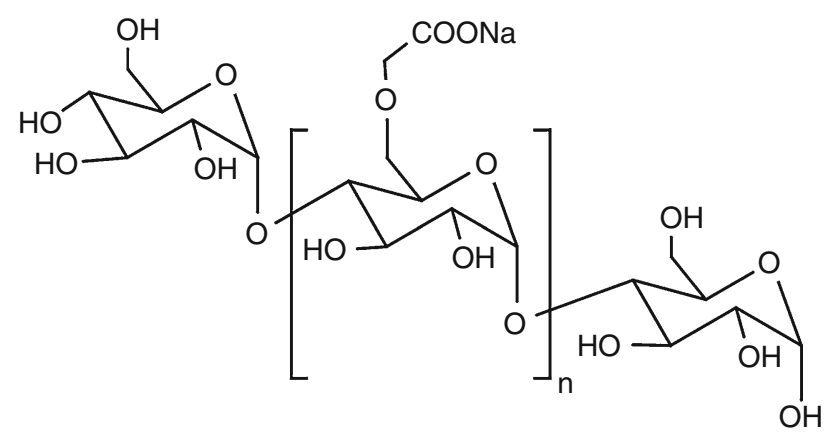

Fig. 1 Amylose fragment with the substitution of the hydrophilic group $-\mathrm{CH}_{2}-\mathrm{COONa}$ in positions 6
Analysis of the thermal decomposition under controlled heating in the aerobic atmosphere in the temperature range of $20-500{ }^{\circ} \mathrm{C}$ was based on the results of thermal analysis methods (TG, DTG, DSC) in combination with the results of spectroscopic (technique DRIFT) in online system.

\section{Experimental}

\section{Material}

In the study, an etherified starch was used in the form of the sodium salt of carboxymethyl starch (CMS-Na; Polvitex ${ }^{\circledR}$ $\mathrm{Z}$ by Xenon) with a degree of substitution DS 0.2 prepared on the basis of native potato starch Superior Standard (80-82\%) comprising: monochloroacetic acid (6-8\%), sodium hydroxide $(3-5 \%)$, sodium carbonate $(3-5 \%)$ and diethylene glycol (3-5\%). Moisture content of the starting product was $6.7 \%$.

\section{Methodology}

\section{Methods of thermal analysis (TG-DTG-DSC)}

Thermal analysis was performed by using a thermal analyzer NETZSCH STA 449 F3 Jupiter ${ }^{\circledR}$ design to simultaneous measurements TG-DTG-DSC, which ensure to obtain independent signals recorded under the same measurement conditions: heating rate, atmosphere and pressure. This method of analysis provided a higher efficiency and allowed obtaining a comprehensive information on the thermal characteristics of the samples of starch products. The measurement was taken under aerobic atmosphere in a temperature range of $20-500{ }^{\circ} \mathrm{C}$ at a gas flow rate of $40 \mathrm{~mL} \min ^{-1}$. The rate of heating of the test sample was $10{ }^{\circ} \mathrm{C} \min ^{-1}$.

\section{DRIFT spectroscopy}

The diffuse reflectance infrared Fourier transform spectroscopy (DRIFTs) is an infrared spectroscopy technique; it can provide both chemical information and structural information for all types of solid surfaces. The DRIFT measurements were taken on the IR spectrometer type FTS 3000 Digilab Excalibur Mx with detector DTGS Bio-Rad, combined with a device for controlling the temperature and cooling system. Spectra were recorded online in the wavenumber range $4000-600 \mathrm{~cm}^{-1}$ assuming a resolution of $8 \mathrm{~cm}^{-1}$, and the number of scans 64 . Interferograms of 64 scans were automatically averaged to a single spectrum.

To measure the diffuse reflectance spectrum of CMS-Na sample, firstly, powdered potassium bromide ( $\mathrm{KBr}$ ) (grain 


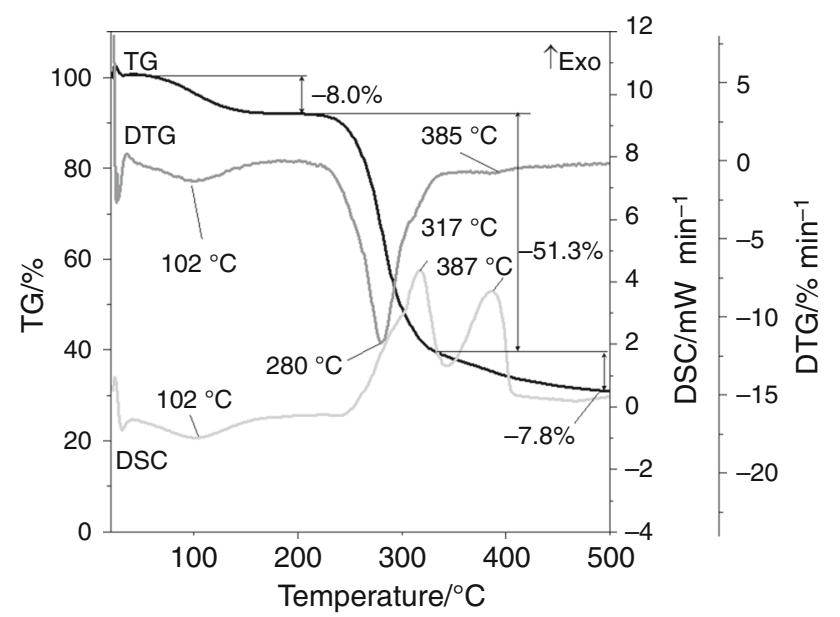

Fig. 2 TG-DTG-DSC curves obtained in an aerobic atmosphere for sample of CMS-Na

size $\leq 2 \mu \mathrm{m}$ ), acting as control, was placed in the diffuse reflectance cup and mounted on the DRIFT attachment to prepare the background measurement. In the next step, the initial sample of CMS-Na (Polvitex ${ }^{\circledR} \mathrm{Z}$ ) was prepared for DRIFT measurements by mechanically grinding to a fine powder with $\mathrm{KBr}$ (CMS-Na/KBr 1:5 ratio) and mounted in DRIFT attachment in the similar manner as described above. Dilution of sample CMS- $\mathrm{Na}$ in $\mathrm{KBr}$ was necessary to reduction the intensity of the bands and distortions in the course of DRIFT spectra. Prepared sample was gradually heated in aerobic atmosphere (air) in the range of $20-500{ }^{\circ} \mathrm{C}$. The first DRIFT spectrum of initial sample was recorded at $20{ }^{\circ} \mathrm{C}$; the next DRIFT spectra of heated sample were recorded after $1 \mathrm{~min}$ from reaching the next desired temperature values during heating of sample to $500{ }^{\circ} \mathrm{C}$ (at 50, 100, 120, 150, 180, 200, 220, 250, 280, 300, $320,350,380,400,420,450,480$ and $\left.500{ }^{\circ} \mathrm{C}\right)$. The heating rate of the test sample was $10{ }^{\circ} \mathrm{C} \mathrm{min}-1$.

\section{Results and discussion}

\section{TG-DTG-DSC thermal analysis}

The course of TG curve proves that the decomposition of CMS-Na takes place with a three-step mass loss: -8.0 ,
$-53.1,-7.8 \%$ in an aerobic atmosphere at speeds of maximum mass changes at temperature $102,280,387^{\circ} \mathrm{C}$, respectively (Fig. 2).

The first mass loss of the sample CMS-Na within a temperature range of $20-120^{\circ} \mathrm{C}$ is interpreted as the evaporation of the water molecules adsorbed on the starch granules and in the range $120-188^{\circ} \mathrm{C}$ assigned to gradual dehydration of the material $[15,16]$. On DSC curve, a weak endothermic effect, related to the removal of moisture from initial sample CMS-Na, is detected around $102{ }^{\circ} \mathrm{C}$.

The degradation process of the sodium salt of carboxymethyl starch begins at temperature above $188^{\circ} \mathrm{C}$. It is evidenced by the highest mass loss in the temperature range of $188-342{ }^{\circ} \mathrm{C}$. This change of mass is assigned an irreversible process of polymer chains fragmentation (breakage of glycosidic bonds), glucopyranose ring opening and formation of volatile products progressively, mainly $\mathrm{CO}, \mathrm{CO}_{2}$ and $\mathrm{H}_{2} \mathrm{O}$ [17]. In the defined temperature range in $280{ }^{\circ} \mathrm{C}$, there was noticed a maximum rate of mass change on DTG curve and the strong exothermic effect on a DSC curves at a temperature of $317^{\circ} \mathrm{C}$. Thermal effects at approx. $300{ }^{\circ} \mathrm{C}$ are typical for the group of natural and modified polysaccharides, and it is associated with receiving the volatile products during thermal degradation [18]. Boki et al. [19] conducted similar research related to thermal decomposition of CMS-Na with DS $\leq 0.3$ in the temperature range of $200-350{ }^{\circ} \mathrm{C}$. Based on above-mentioned paper and our results, it can be noted that the course of mass changes on TG curves and onset temperature of decomposition of CMS-Na (Polvitex ${ }^{\circledR} \mathrm{Z}$ ) approx. $260{ }^{\circ} \mathrm{C}$ are comparable. The most visible difference is the presence of the two strong exothermic effects at 260 and $295^{\circ} \mathrm{C}$ on DCS curves detected by Boki et al. [19] in the defined temperature range.

In the temperature range of $342-500{ }^{\circ} \mathrm{C}$, the mass loss is associated with much less efficient course of material degradation and detachment of the side groups -COONa. At the temperature of $387{ }^{\circ} \mathrm{C}$, a strong exothermic peak is detected, which may be associated with a combustion of carboxymethyl starch sodium in an aerobic atmosphere.

In the analyzed temperature range of $20-500{ }^{\circ} \mathrm{C}$, the sample is not completely decomposed and at a temperature of $500{ }^{\circ} \mathrm{C}$ the residual mass of sample is $30.9 \%$.

Table 1 Analysis of TG-DTG-DSC curves in the range of $20-500{ }^{\circ} \mathrm{C}$ obtained for sample of CMS-Na

\begin{tabular}{lcccc}
\hline Stage & Mass loss $\Delta m / \%$ & $\begin{array}{l}\text { Range of } \\
\text { temperature } /{ }^{\circ} \mathrm{C}\end{array}$ & $\begin{array}{l}\text { Temperature of maximum } \\
\text { rate of mass loss } /{ }^{\circ} \mathrm{C}\end{array}$ & $\begin{array}{l}\text { DSC effect } \\
\text { temperature } /{ }^{\circ} \mathrm{C}\end{array}$ \\
\hline I & -8.0 & $20-188$ & 102 & Endo-102 \\
II & -53.3 & $188-342$ & 280 & Exo-317 \\
III & -7.8 & $342-500$ & 385 & Exo-387 \\
Residual mass: $30.9 \%\left(500{ }^{\circ} \mathrm{C}\right)$ & & & & \\
\hline
\end{tabular}


Incomplete decomposition of CMS-Na is probably related to the presence of sodium atoms in the sample. Sodium plays a key role in thermal decomposition of modified starch by influence on the efficiency of the dehydration, decarboxylation, carbonizing the material and the volatile substances of higher molecular mass and carbon oxides formation $[15,20]$. Table 1 summarizes the characteristic thermal data selected from the TG-DTG-DSC curves for a sample of CMS-Na (Polvitex ${ }^{\circledR} \mathrm{Z}$ ).

\section{Spectroscopic analysis}

The analysis of the impact of increasing temperature on the structure of the investigated material was carried out with regard to the disappearance or the formation of bands on the spectra. The DRIFT spectra recorded within the temperature range of $20-500{ }^{\circ} \mathrm{C}$ for sample of low-substituted CMS-Na are presented in Fig. 3.

Initially, within the temperature range of $20-200{ }^{\circ} \mathrm{C}$ there are observed changes in the area assigned to interand intramolecular $\mathrm{O}-\mathrm{H}$ groups [21]. These changes are associated with the elimination of water from the polymer chain (bound water and constitutional water). As a result of temperature rising, in the range of the wavenumber $3900-2900 \mathrm{~cm}^{-1}$, there is observed change of the position of the two maxima of the bands assigned to hydroxyl groups. At $20{ }^{\circ} \mathrm{C}$ in the range of wavenumber $3000-2900$ $\mathrm{cm}^{-1}$, there is one band with a maximum at $3586 \mathrm{~cm}^{-1}$ and a second band with a peak at around $3199 \mathrm{~cm}^{-1}$. At rising temperature, maxima of this bands are shifted to the 3545 , and $3291 \mathrm{~cm}^{-1}$, respectively. This shows the intensive evaporation of water and the partially disappearance of existing hydrogen bonding between polymer chains of CMS-Na. However, the intensity of the bands assigned to OH group in the DRIFT spectra is not completely reduced in the temperature range of $20-200{ }^{\circ} \mathrm{C}$, so there also may indicate to cross-linking of the polymer chains by hydrogen bonds [5].

Furthermore, the process of eliminating water adsorbed on the starch macromolecules from the sample CMS-Na is confirmed by the change of intensity of band near the wavenumber $1643 \mathrm{~cm}^{-1}$, which disappears completely above $120^{\circ} \mathrm{C}[21,22]$.

On the DRIFT spectra recorded at above $120{ }^{\circ} \mathrm{C}$, a new band in the range of wavenumber $1670-1820 \mathrm{~cm}^{-1}$ (maximum of peak at $1664 \mathrm{~cm}^{-1}$ ) corresponding to the vibration of the carbonyl group forming a $\mathrm{C}=\mathrm{O}$ is occurred. The recorded vibration of the $\mathrm{C}=\mathrm{O}$ may be related to both the formation of aldehydes, ketones, esters from the sample $[17,21,23]$. In the subsequent heating steps above $300{ }^{\circ} \mathrm{C}$,

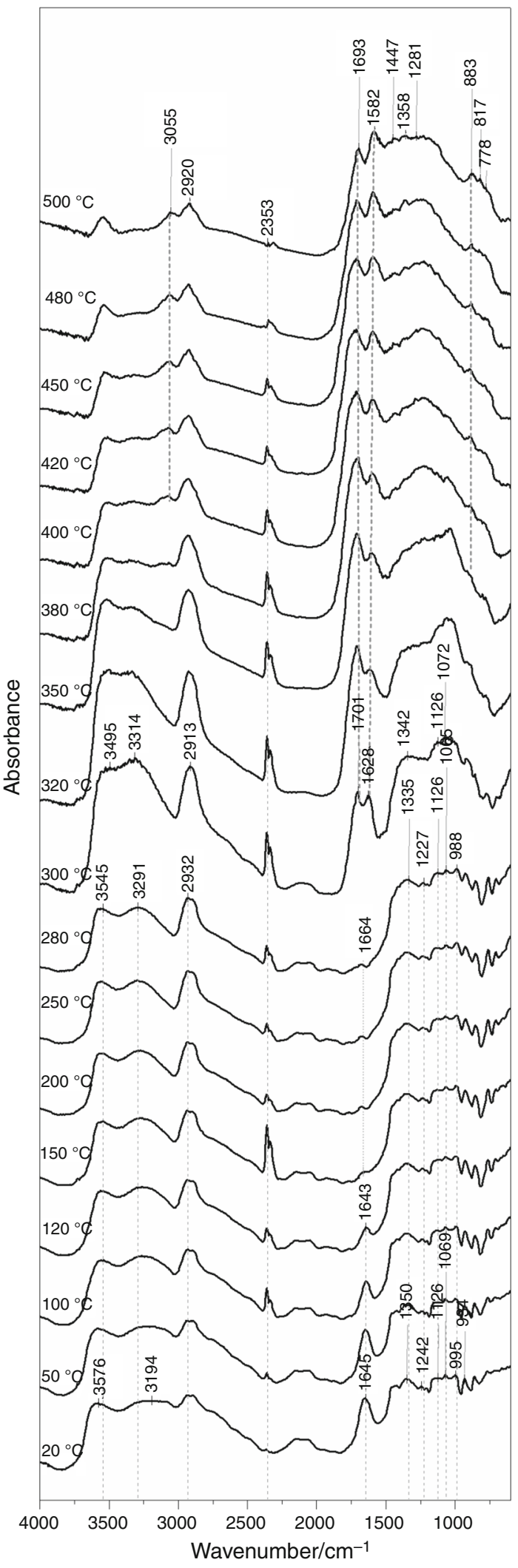

Fig. 3 DRIFT spectra recorded in the range of $20-500{ }^{\circ} \mathrm{C}$ for samples of CMS-Na 
two bands are separated from this band, and maximum of band corresponding to the $\mathrm{C}=\mathrm{O}$ group is shifted to higher wavenumbers. Boki et al. [19] in their research also carried out research on structural changes between initial and decomposed sample of CMS-Na with $\mathrm{DS} \leq 0.3$. Based on IR spectra obtained by transmittance spectroscopy, Boki et al. noticed that main result of thermal decomposition of CMS-Na in temperature range $200-350{ }^{\circ} \mathrm{C}$ was change of the intensity band with maximum at $1600 \mathrm{~cm}^{-1}$ assigned to vibration of carbonyl $(\mathrm{C}=\mathrm{O})$ and carboxylate $\left(-\mathrm{COO}^{-}\right)$groups. This effect was probably caused by partial decomposition of carboxymethyl group in lowsubstituted CMS-Na [19]. That effect is not clearly observed on DRIFT spectra obtained for initial and thermally decomposed sample of CMS-Na (Polvitex ${ }^{\circledR} \mathrm{Z}$ ) analyzed in this paper. But optical phenomena that generate DRIFT signals are different from those involved in transmittance spectroscopy; therefore, the spectra obtained by these methods cannot be considered equivalent.

The irreversible structural changes in the sample indicating degradation of the material are recorded in the temperature range of above $300{ }^{\circ} \mathrm{C}$. The new bands appear in area of the wavenumber $3000-3100 \mathrm{~cm}^{-1}$ (peak at $3055 \mathrm{~cm}^{-1}$ ), $1700-1500 \mathrm{~cm}^{-1}$ (maximum $\sim 1574 \mathrm{~cm}^{-1}$ ) and $900-650 \mathrm{~cm}^{-1}$ (three peaks at $876,814,777 \mathrm{~cm}^{-1}$ ). They are identified as: stretching vibration of the $\mathrm{C}-\mathrm{H}$ vibrations of the $\mathrm{C}=\mathrm{C}$ stretching of the ring, and a few bands in the fingerprint range $\left(800-1500 \mathrm{~cm}^{-1}\right)$ relating to aromatic $\mathrm{C}-\mathrm{H}$ out-of-plane bending vibrations. The presence of these bands and increase in their intensity can indicate the progressive process formation of aromatic compounds [21]. In the lower wavenumber above $300{ }^{\circ} \mathrm{C}$, it is also observed the disappearance of the band corresponding to the bonding characteristic $\mathrm{C}-\mathrm{O}-\mathrm{C}$ in modified starch and shifting its maximum from $930 \mathrm{~cm}^{-1}$ to the lower wavenumbers. The changes in the wavenumber range are associated with irreversible cracking of many glycosidic linkages between glucopyranose ring of amylose and amylopectin chains in CMS-Na [24].

\section{Conclusions}

The results of thermal stability studies obtained by methods of thermal analysis TG-DTG-DSC and spectroscopic method by DRIFT technique allowed to determine a complex course of the next stages of thermal decomposition of the binder under the aerobic atmosphere measurement conditions. Thermal decomposition mechanism of the binder in the form of CMS-Na is a multistage process, and based on the curve TG-DTG-DSC and DRIFT spectra course, it can be concluded that:
- evaporation of adsorbed water molecule sodium carboxymethyl starch occurs at the temperature of $20-120{ }^{\circ} \mathrm{C}$;

- dehydration and formation of the network of hydrogen bonds are observed in the range of $120-200{ }^{\circ} \mathrm{C}$;

- breakage of glycosidic bonds in the polymer chains intense the fragmentation chain, the formation of carbonyl groups (it indicates the presence of aldehydes, ketones or esters as a decomposition product) and the formation of volatile compounds are recorded in the range of $\sim 200-342{ }^{\circ} \mathrm{C}$;

- above the temperature of $188{ }^{\circ} \mathrm{C}$, the process of degradation of the binder begins, but the most intense structural changes are recorded over $280{ }^{\circ} \mathrm{C}$. In this temperature range, the thermal decomposition reactions were observed associated with the formation of bonds characteristic for aromatic moieties.

Sample of CMS-Na is not completely decomposed in the temperature range of $20-500{ }^{\circ} \mathrm{C}$, leaving a residual mass of $30.9 \%$ at $500{ }^{\circ} \mathrm{C}$.

Acknowledgements The work was supported by Polish Ministry of Science and Higher Education under Dean's Grant AGH UST No. 15.11.170.541.

Open Access This article is distributed under the terms of the Creative Commons Attribution 4.0 International License (http://creativecommons. org/licenses/by/4.0/), which permits unrestricted use, distribution, and reproduction in any medium, provided you give appropriate credit to the original author(s) and the source, provide a link to the Creative Commons license, and indicate if changes were made.

\section{References}

1. Major-Gabryś K. Biodegradable materials as foundry moulding sands binders. Metalurgija. 2014;54:591-3.

2. Kaczmarska K, Grabowska B, Drożyński D, Bobrowski A, Kurleto Ż, Szymański Ł. Modified polysaccharides as alternative binders for foundry industry. Metalurgija. 2016;55:839-42.

3. Yu W, He H, Cheng N, Gan B, Li X. Preparation and experiments for a novel kind of foundry core binder made from modified potato starch. Mater Des. 2009;30:210-3.

4. Zhou X, Yang J, Qu G. Study on synthesis and properties of modified starch binder for foundry. J Mater Process Technol. 2007;183:407-11.

5. Grabowska B, Sitarz M, Olejnik E, Kaczmarska K. FT-IR and FT-Raman studies of cross-linking processes with $\mathrm{Ca}^{2+}$ ions, glutaraldehyde and microwave radiation for polymer composition of poly(acrylic acid)/sodium salt of carboxymethyl starch: part I. Spectrochim. Acta A Mol Biomol Spectrosc. 2015;131:529-35.

6. Grabowska B, Sitarz M, Olejnik E, Kaczmarska K, Tyliszczak B. FT-IR and FT-Raman studies of cross-linking processes with $\mathrm{Ca}^{2+}$ ions, glutaraldehyde and microwave radiation for polymer composition of poly(acrylic acid)/sodium salt of carboxymethyl starch-in moulding sands, part II. Spectrochim. Acta A Mol Biomol Spectrosc. 2015;151:27-33.

7. Spychaj T, Zdanowicz M, Kujawa J, Schmidt B. Carboxymethyl starch with high degree of substitution: synthesis, properties and application. Polimery. 2013;58:501-630. 
8. Spychaj T, Wilpiszewska K, Zdanowicz M. Medium and high substituted carboxymethyl starch: synthesis, characterization and application. Starch-Stärke. 2013;65:22-33.

9. Kaczmarska K, Grabowska B. Potential of the application of the modified polysaccharides water solutions as binders. Metalurgija. 2016;55:15-8.

10. Fox JT, Cannon FS, Brown NR, Huang H, Furness JC. Comparison of a new, green foundry binder with conventional foundry binders. Int J Adhes Adhes. 2012;34:38-45.

11. Brown J, editor. Sands and green sand Silica. Foseco ferrous Foundryman's Handbook. Oxford: Butterworth-Heinemann; 2000.

12. Łucarz M. Setting temperature for thermal reclamation of used moulding sands on the basis of thermal. Metalurgija. 2015;54:319-22.

13. Łucarz M. Thermal reclamation of the used moulding sands. Metalurgija. 2015;54:109-12.

14. Grabowska B, Malinowski P, Szucki M, Byczyński Ł. Thermal analysis in foundry technology. $\mathrm{J}$ Therm Anal Calorim. 2016;126:245-50.

15. Liu X, Wang Y, Yu L, Tong Z, Chen L, Liu H, et al. Thermal degradation and stability of starch under different processing conditions. Starch-Stärke. 2013;65:48-60.

16. Leivas CL, Da Costa FJOG, De Almeida RR, De Freitas RJS, Stertz SC, Schnitzler E. Structural, physico-chemical, thermal and pasting properties of potato (Solanum tuberosum L.) flour: study of different cultivars and granulometries. J Therm Anal Calorim. 2013;111:2211-6.
17. Pielichowski K, Njuguna J. Thermal degradation of polymeric materials. Billingham: Rapra Technology Limited; 2005.

18. Hornung PS, do Prado Cordoba L, da Silveira Lazzarotto SR, Schnitzler E, Lazzarotto M, Ribani RH. Brazilian Dioscoreaceas starches. Thermal, structural and rheological properties compared to commercial starches. J Therm Anal Calorim. 2017;127:1869-77.

19. Boki K, Kimura D, Minami K, Yamada Y. Thermal decomposition of sodium carboxymethyl starch. Jpn J Toxicol Environ Health. 1998;44:204-13.

20. Jakab E. Analytical techniques as a tool to understand the reaction mechanism. In: Pandey A, Bhaskar T, editors. Recent advances in thermo-chemical conversion biomass. Amsterdam: Elsevier; 2016.

21. Budarin V, Clark JH, Hardy JJE, Luque R, Milkowski K, Tavener SJ, et al. Starbons: new starch-derived mesoporous carbonaceous materials with tunable properties. Angew Chem Int Ed. 2006;45: 3782-6.

22. Capek P, Drabik M, Turjan J. Characterization of starch and its mono and hybrid derivatives by thermal analysis and FT-IR spectroscopy. J Therm Anal Calorim. 2010;99:667-73.

23. Shuttleworth PS, Budarin V, White RJ, Gun'Ko VM, Luque R, Clark JH. Molecular-level understanding of the carbonisation of polysaccharides. Chem A Eur J. 2013;19:9351-7.

24. Zhang X, Golding J, Burgar I. Thermal decomposition chemistry of starch studied by ${ }^{13} \mathrm{C}$ high-resolution solid-state NMR spectroscopy. Polymer (Guildf). 2002;43:5791-6. 